\title{
Irrigation-Induced Land-Atmosphere Feedbacks and Their Impacts on Indian Summer Monsoon $\mathscr{0}$
}

\author{
Chinchung Chou And Dongryeol Ryu \\ Department of Infrastructure Engineering, University of Melbourne, Parkville, Victoria, Australia \\ Min-Hui Lo AND HAO-WEI WEY ${ }^{\mathrm{a}}$ \\ Department of Atmospheric Sciences, National Taiwan University, Taipei, Taiwan \\ HECTOR M. MALANO \\ Department of Infrastructure Engineering, University of Melbourne, Parkville, Victoria, Australia
}

(Manuscript received 8 November 2017, in final form 19 July 2018)

\begin{abstract}
From the 1980s, Indian summer monsoon rainfall (ISMR) shows a decreasing trend over north and northwest India, and there was a significant observed reduction in July over central and south India in 19822003. The key drivers of the changed ISMR, however, remain unclear. It was hypothesized that the large-scale irrigation development that started in the 1950s has resulted in land surface cooling, which slowed large-scale atmospheric circulation, exerting significant influences on ISMR. To test this hypothesis, a fully coupled model, the CESM v1.0.3, was used with a global irrigation dataset. In this study, spatially varying irrigationinduced feedback mechanisms are investigated in detail at different stages of the monsoon. Results show that soil moisture and evapotranspiration increase significantly over India throughout the summertime because of the irrigation. However, 2-m air temperature shows a significant reduction only in a limited region because the temperature change is influenced simultaneously by surface incoming shortwave radiation and evaporative cooling resulting from the irrigation, especially over the heavily irrigated region. Irrigation also induces a 925-hPa northeasterly wind from $30^{\circ} \mathrm{N}$ toward the equator. This is opposite to the prevailing direction of the Indian summer monsoon (ISM) wind that brings moist air to India. The modeled rainfall in the irrigated case significantly decreases up to $1.5 \mathrm{~mm}$ day $^{-1}$ over central and north India from July to September. This paper reveals that the irrigation can contribute to both increasing and decreasing the surface temperature via multiple feedback mechanisms. The net effect is to weaken the ISM with the high spatial and temporal heterogeneity.
\end{abstract}

\section{Introduction}

The Indian summer monsoon rainfall (ISMR), contributing $85 \%$ of annual rainfall in India, has undergone several noticeable changes in past decades (Singh et al. 2014). Specifically, ISMR showed a negative long-term trend in

Supplemental information related to this paper is available at the Journals Online website: https://doi.org/10.1175/JCLI-D-17-0762.s1.

\footnotetext{
${ }^{a}$ Current affiliation: Max Planck Institute for Meteorology, Hamburg, Germany.
}

Corresponding author: Chihchung Chou, chihchungc@student. unimelb.edu.au
1980-2015 compared to the expected level from previous observational rainfall records during the period 18712012 (Naidu et al. 2015). Lee et al. (2009) also analyzed the observations in 1982-2003 and found that there were significantly decreasing trends in the early ISMR (July) over central $\left(-2 \mathrm{~mm} \mathrm{day}^{-1} \mathrm{decade}^{-1}\right)$ and south $\left(-0.5 \mathrm{~mm} \mathrm{day}^{-1}\right.$ decade $\left.^{-1}\right)$ India. Furthermore, there was a significantly decreasing trend in monsoon rainfall data from the Indian Meteorological Department (IMD) over north and northwest India in 1951-2003 (Niyogi et al. 2010).

There are several factors that potentially contributed to the observed changes in ISMR. These include changed El Niño-Southern Oscillation (ENSO; Dwivedi et al. 2015), sea surface temperature (SST) 
variability (Saji et al. 1999; Salzmann and Cherian 2015), anthropogenic aerosols (Bollasina et al. 2011, 2014), largescale agricultural irrigation (Lee et al. 2009; Puma and Cook 2010), and land-use and land-cover change (LULCC; Halder et al. 2016; Kueppers et al. 2007; Xu et al. 2015). For example, it is argued that the warming SST in the Indian Ocean, along with a relatively cooler land surface over the Indian subcontinent, plays a key role in the decreased ISMR (Roxy et al. 2015). Also, the observed drying is partially ascribed to anthropogenic aerosol because of its important role in an earlier monsoon onset and rainfall enhancement due to changes in lower-tropospheric wind field and temperature (Bollasina et al. 2014). In terms of LULCC, the forest-to-cropland simulations indicate that LULCC can cause considerable variability in 2-m air temperature and an anticyclonic anomaly at low-level atmosphere in India (Xu et al. 2015).

However, the combined effect of the above-listed candidates influencing ISMR makes the net effect conditional and difficult to predict. It was reported, for example, that the relationship between ENSO and monsoon started weakening from the 1980s onward (Kumar et al. 1999). Also, Srivastava et al. (2015) showed that the correlation between the SST index in the Niño-3 region from the National Centers for Environmental Prediction-National Center for Atmospheric Research (NCEP-NCAR) reanalysis and ISMR weakened in 1981-2010 because of the increasing influence from extratropical circulation. The human-induced aerosol is known to be responsible for the reduced rainfall over north-central India via weakening meridional overturning circulation in the tropics (Bollasina et al. 2011), but the large uncertainty and limited availability of the aerosol dataset (Bollasina et al. 2014) hampers accurate quantification of its effect on ISMR. These examples indicate the importance of process-based understanding on individual factors influencing ISMR to improve the prediction of their combined effect.

In this work, we investigate the processes involved in the ISMR changes in response to the irrigation-induced soil moisture anomaly. Agricultural irrigation development in India grew steadily from the 1950s, leading to a considerable growth of the irrigated area and irrigation water volume (Siebert et al. 2015; Wisser et al. 2008). The increases in water vapor flux (Boucher et al. 2004) and evapotranspiration (ET) induced by the large-scale agricultural irrigation can modulate land surface temperature and local atmospheric circulation, which, in turn, have a remote effect on the adjacent regions (Lo and Famiglietti 2013). Using a general circulation model, Puma and Cook (2010) demonstrated that irrigation caused a land surface cooling (Lobell et al. 2009; Sacks et al. 2009) in the Northern Hemisphere during summertime with a negative anomaly of June-August rainfall in India from the mid-1970s to 2000. Cook et al. (2015) also found a significant reduction in simulated ISMR (including Bangladesh) caused by irrigation, which was also discussed in other studies (Guimberteau et al. 2012; Saeed et al. 2009, 2013; Shukla et al. 2014; Thiery et al. 2017). At a regional scale, Saeed et al. (2009) argued that irrigation led to increased rain over the Indus and Ganges River basins.

The irrigation-induced decrease in precipitation is linked to land surface cooling and a reduced available energy in the overlying atmosphere in India (Zeng et al. 2017). Furthermore, Zeng et al. (2017) demonstrate a wind anomaly caused by irrigation over northern India in the partially coupled (CAM and CLM) simulations, flowing from the Indian subcontinent to either the Bay of Bengal or the Arabian Sea depending on the uncertainty of background climate change. The climate and land surface responses to groundwater irrigation were also investigated in previous researches (Zou et al. 2014, 2015). As the soil moisture-precipitation feedback loop reported in Fig. 10 of Seneviratne et al. (2010), the positive (negative) feedback in this work refers to the increased (decreased) ISMR in response to the irrigation-induced positive soil moisture anomaly. Despite the above studies reporting the increase/decrease in ISMR, detailed potential processes forming the positive or negative feedbacks and the associated role of large-scale atmospheric circulation at the different stages of summertime have not been discussed with enough details. The current study, therefore, aims to reveal the series of change arising between the irrigation-induced soil moisture anomaly and ISMR (we consider ISMR as rainfall from June to September) in the context of large-scale atmospheric circulation. This can provide valuable insights to understanding complex feedback mechanisms between the irrigation and ISMR. The comparison of rainfall between simulations and observations is, first, demonstrated to evaluate the overall model performance. Next, investigating the changes in energy heat fluxes, surface incoming shortwave radiation, low cloud cover, and surface temperature at different stages of summertime would help to reveal the potential mechanisms for the changed rainfall. After that, with the analysis of large-scale atmospheric circulation change, the impact of irrigation on the local and remote region will be discussed together.

\section{Model and data}

Two numerical experiments, previously conducted by Wey et al. (2015), with and without irrigation using a fully coupled land-atmosphere-ocean model, the 
Community Earth System Model (CESM v1.0.3; Hurrell et al. 2013), were analyzed to understand the effect of irrigation on ISMR in this study. The model applies the Community Land Model, version 4 (CLM4), of the improved performance of simulating the land hydrological processes, the advanced Community Atmosphere Model, version 5 (CAM5), and the Parallel Ocean Program, version 2 (POP2). Specifically, a revised numerical solution of the Richard's equation was applied within the hydrological process in CLM4, and a new evaporation parameterization accounts for the canopy stability and litter. The irrigation water demand dataset (Wisser et al. 2008) was used to run the irrigated case (see text S2 in the online supplemental material for more details). Here, the approaches implemented in Wisser et al. (2008) are briefly described as follows. First, the natural rain and the above dataset were added directly to soil water content up to the level of waterholding capacity when it was below the crop-specific threshold level (Wisser et al. 2008). Second, for rice, Wisser et al. (2008) assumed that 50-mm-deep water above the ground was maintained during the growing period with seepage into soil at a fixed rate. Finally, the gross irrigation water quantity was calculated based on the net irrigation water demand and the irrigation efficiency for South Asia [0.35; see Table 1 in Döll and Siebert (2002)]. Interannual variability of the above dataset in 1991-2000 (represented by the standard deviation) is $10 \%$ or less of the mean irrigation in the same period (see details in text S2). The map of the simulated average irrigation water demand in 1991-2000 is shown in Fig. 1.

Two model simulations for a control case (denoted by CTRL hereafter) and an irrigated case (denoted by IRR hereafter) were conducted in the fully coupled mode with a horizontal resolution of $1.9^{\circ} \times 2.5^{\circ}$. The only difference between the two cases is that, for the IRR case, the global irrigation water data were evenly applied to the whole grid cell at the top layer of the soil column bypassing the canopy layer. Application of the irrigation water over the whole grid cell used in this study may overestimate ET compared to the irrigation simulation based on the plant functional types (PFTs) due to the evenly applied irrigation over the nonagricultural fraction of the grids. However, the air temperature and energy fluxes are averaged over the grid cells to be coupled with the atmospheric model; thus, the corresponding atmospheric processes are not modulated significantly (Schultz et al. 2016). To simplify the configuration, therefore, irrigation water was added to the whole grid cell in the IRR case assuming that the PFT-level bias in energy flux is negligible. The groundwater-sourced irrigation was extracted from the "unconfined aquifer" of the CLM; consequently, the feedback to soil water and recharge rate should be propagated realistically (see text S3 in the supplemental material for more information). With the interannually invariant forcing [including all major anthropogenic influences such as greenhouse gases (GHGs) and aerosols] of year 2000, the first 50 years of a 100-yr period were considered as a spinup, and only the results from the second 50 years were analyzed. By showing the second 50 years' average variables, this study aims to determine the sensitivity of the land surface and climatic responses to irrigation in a perspective of relative change from the CTRL to IRR run (see text S4 in the supplemental material for model stabilization). More detailed configuration of the numerical experiments can be found in Wey et al. (2015).

The following observational datasets were compared and verified with the simulated results. The observational monthly near-surface temperature dataset in 1901-2012 is from Climatic Research Unit (CRU) Time Series 3.2 (Harris et al. 2014). The monthly rainfall dataset in 1871-2013 from the Indian Institute of Tropical Meteorology (IITM) (see https://www. tropmet.res.in/) was prepared by assigning the district area as the weight for each rain gauge station in that subdivision. Since the simulation was undertaken with a single-year forcing, assessing the plausibility of the output rainfall cannot be made by direct comparison with the IITM's observation data. Instead, we compared the rainfall difference between the CTRL and IRR simulations with the decrease in ISMR estimated following the proposal by Naidu et al. (2015). Based on the long-term fluctuation of 21-yr-moving-average rainfall data, Naidu et al. (2015) argued a reduction of rainfall in the last 30 years of the analysis period 1871-2012. It was reported that ISMR fluctuates with an approximately 60 -yr cycle (Agnihotri et al. 2002). Additionally, it has been confirmed that the multidecadal variability of ISMR is modulated by the Atlantic multidecadal oscillation (AMO) through the tropospheric temperature anomaly over Eurasia and the shift of the Walker circulation related to the regional Hadley circulation (Goswami et al. 2006).

Since the Green Revolution in India started in the 1950s with a rapid growth from the 1970s, we assumed that the impact of irrigation development on ISMR was negligible in 1881-1971. Based on the reported cyclic features of ISMR and the timing of the irrigation development, a hypothetical "baseline" ISMR cycle was constructed by fitting a sinusoidal function with a linear trend (additive) to the time series of 21-yrmoving-average ISMR in 1881-1971. The baseline series represents the moving-averaged ISMR that would have occurred without the influence of the irrigation 


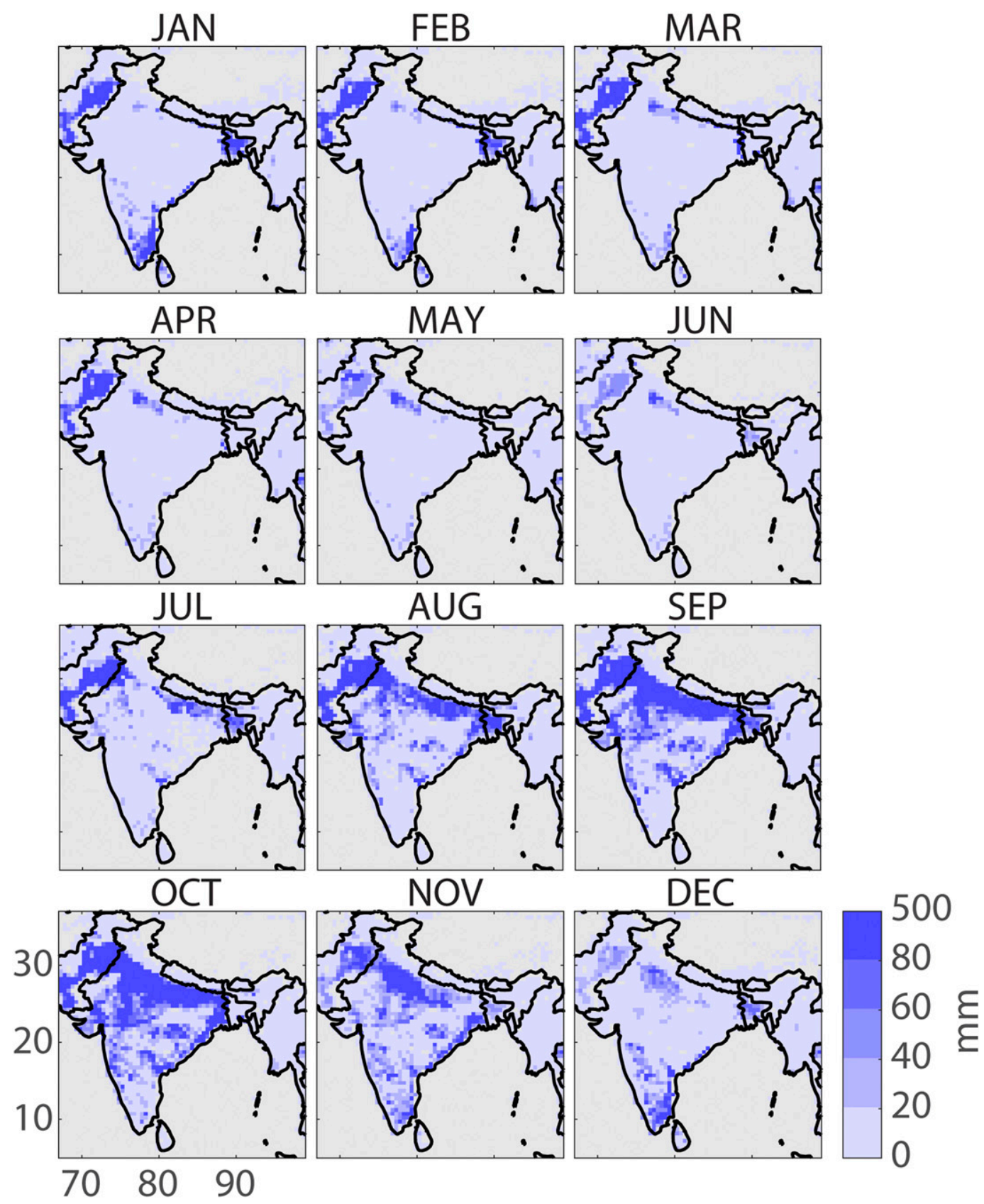

FIG. 1. Monthly spatial maps of the applied irrigation water averaged over the period 1991-2000.

development or other possible influences that commenced after 1971. Consequently, it was assumed that the difference between the 21-yr moving average of ISMR and the baseline series in 1972-2013 was partially caused by the irrigation development on ISMR during the corresponding period. Finally, this projected difference was compared with the difference of ISMR between CTRL and IRR simulations. More details can be found in the supporting information. The Student's $t$ test was applied to identify the statistical significance of the difference between the CTRL and IRR cases.

\section{Results}

\section{a. Changes in monthly rainfall}

Since the two runs were undertaken giving the year2000 forcing in each year of the simulation, the simulated rainfall is compared to the IMD observation of the 


\section{Rainfall data in 'CTRL' case (50-year average, upper) and IMD Rainfall (in 2000, bottom)}

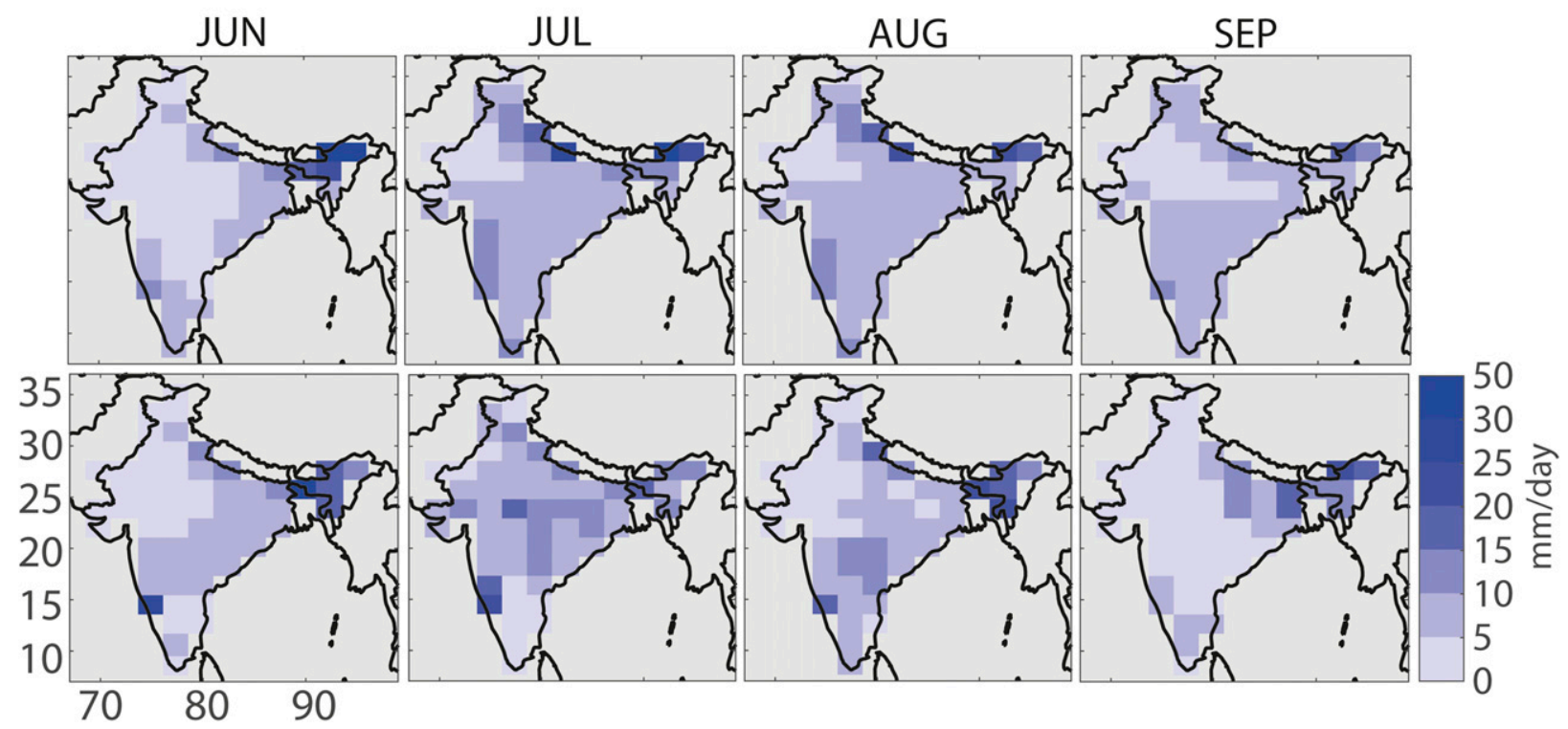

FIG. 2. Comparison of monthly rainfall between the (top) CTRL case (the 50-yr average) and the (bottom) IMD observation in 2000.

year 2000 to evaluate the model performance before analyzing the difference between two runs. The $0.5^{\circ}$ IMD observational rain dataset in 2000 was aggregated into the model resolution $\left(2.5^{\circ} \times 1.9^{\circ}\right)$, and only the simulated rainfall in the second 50 years is averaged to compare with. As shown in Fig. 2, although the simulated rainfall is slightly higher over south (central) India in July (September), the model performance is reasonable in both qualitative and quantitative aspects. The differences could partially be due to the lower resolution used in the simulations.

Interannual variability of rainfall is greater in summer than in winter since the large-scale rainfall events mostly occur in summer. In general, the difference in individual monthly rainfall values between the CTRL and IRR cases is large in May-October over India with high interannual variability, but the 50 -yr mean rainfall of the IRR case exhibits a statistically significant increase ( $p<$ 0.05; see boxplots in Fig. S1) only in March. This is possibly due to the high subregional spatial heterogeneity of rainfall that is averaged out when it is summarized over the entirety of India. Furthermore, the high interannual variability of ISMR reported in the previous studies (Chase et al. 2003; Naidu et al. 2015; Singh et al. 2014) shown in scatterplots in Fig. S1 can also contribute to the weak statistical significance of the change in ISMR.

Figure 3 shows the high spatial variability of the difference in average monthly rainfall between the two cases, in particular from June to September. Rainfall throughout most northern regions in July significantly $(p<0.05)$ decreased by approximately $1 \mathrm{~mm} \mathrm{day}^{-1}$ while insignificant reductions in rainfall were widespread in June, the monsoon onset month. Rainfall kept reducing in August and September but in different areas. In August, a reduction of rain dominated over the limited regions of northwest states like Punjab and Haryana, but with increases in the northern Arabic Sea and the northern Bay of Bengal. Rain decreased in the eastern half of the Indian subcontinent and the northern Bay of Bengal in September.

From July to September, some of the moderately to heavily irrigated regions (e.g., the northwest region in Fig. 1) with a less-than-expected rainfall reduction coincide with the areas with increased low cloud cover (see top row of Fig. 4). This may be associated with the possible growth of a positive feedback such as the enhancement of moisture at the lower atmosphere or the increased ET-related rainfall recycling (Koster et al. 2004; Pathak et al. 2014). The net result of the trivial increase in rainfall in September indicates that there might be a regional-scale negative feedback mechanism between the irrigation-induced soil moisture anomaly and rainfall, which offsets the positive feedback at larger scale. The decrease in rainfall during summertime, such as in July, will be discussed in section 3c(2) with the weakened large-scale atmospheric circulation. 

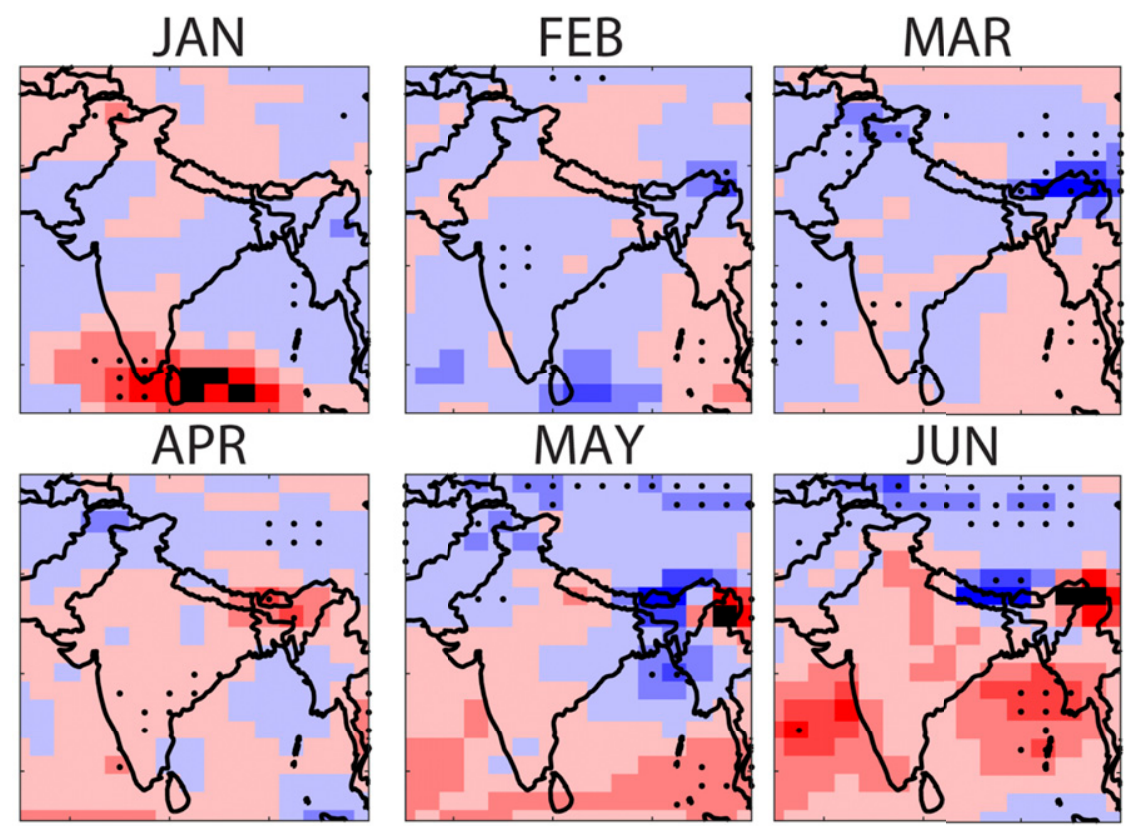

JUL
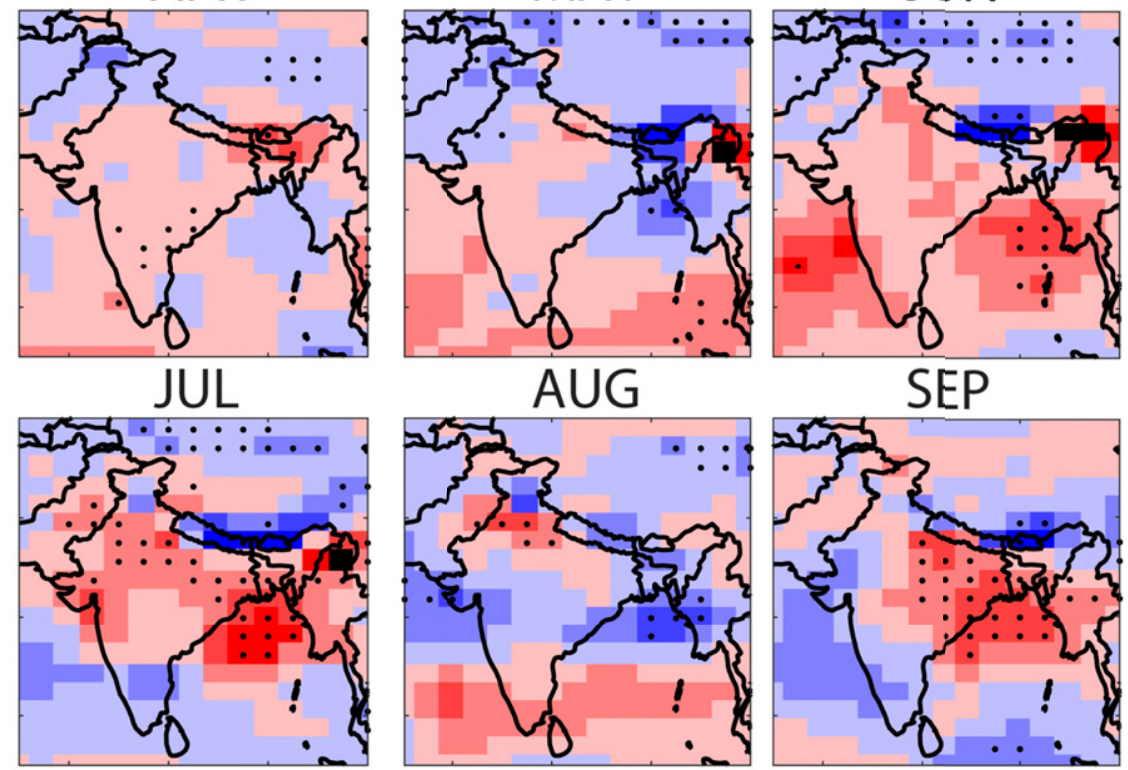

AUG
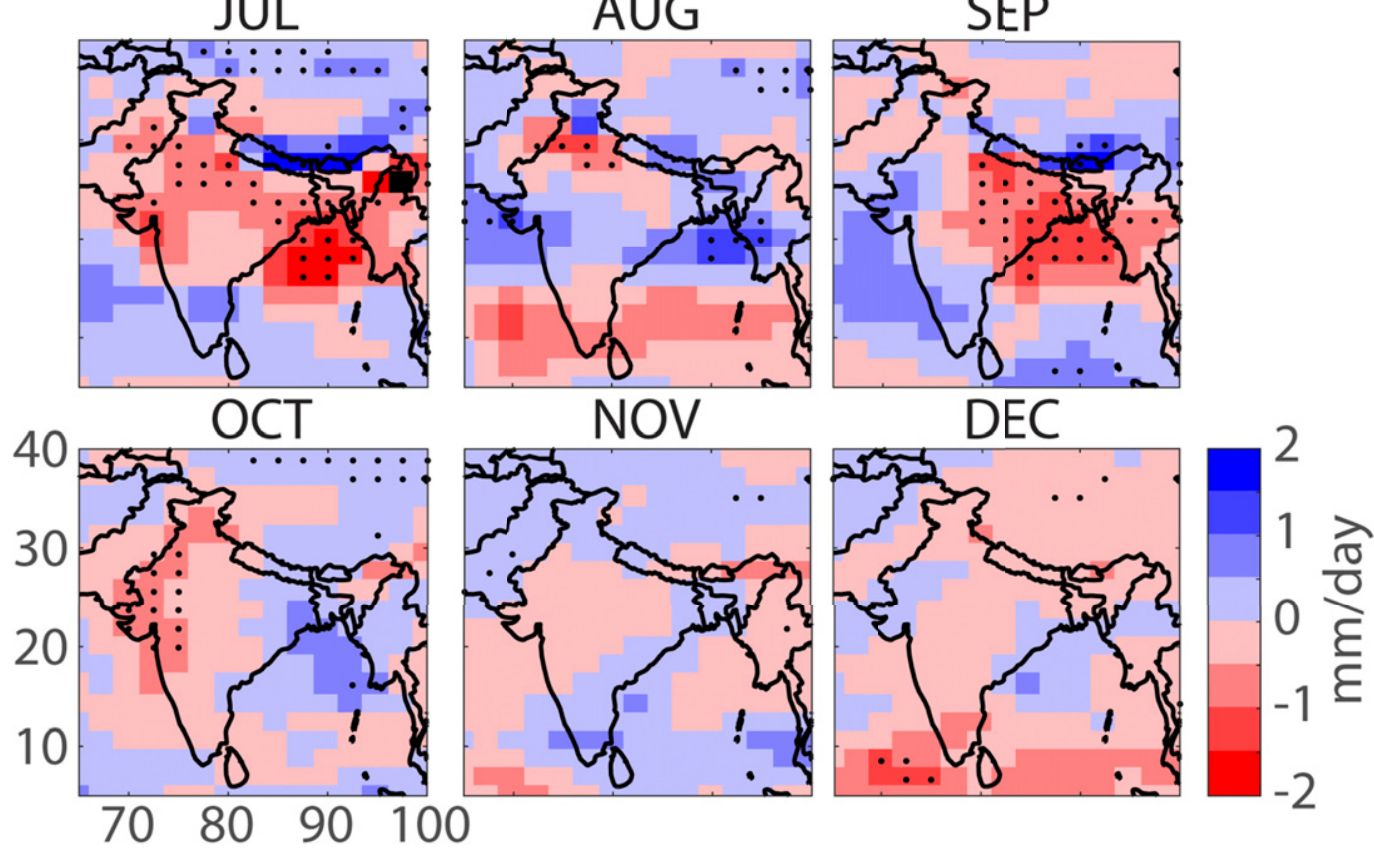

FIG. 3. The 50-yr-average changes in monthly rainfall (IRR minus CTRL; black dots mark grid cells with $p<0.05$ ).

The decrease in rainfall spreads along the western boundary of India in October.

\section{b. Comparison between the projected and simulated difference of ISMR}

In this section, the simulated difference in ISMR between IRR and CTRL runs is compared with the difference between the IITM observation and a hypothetical background ISMR without the factors that influenced ISMR from the 1950s. Following Naidu et al. (2015), we assumed that the background ISMR features a multidecadal periodicity and that deviations from the background trend can be quantified more distinctively when its annual time series is smoothed to emphasize the trend. Berkelhammer et al. (2010) also suggested multidecadal variability of ISMR using a 1000-yr oxygen isotope record from the Danak Cave in east-central India. The simulated change (IRR - CTRL) 


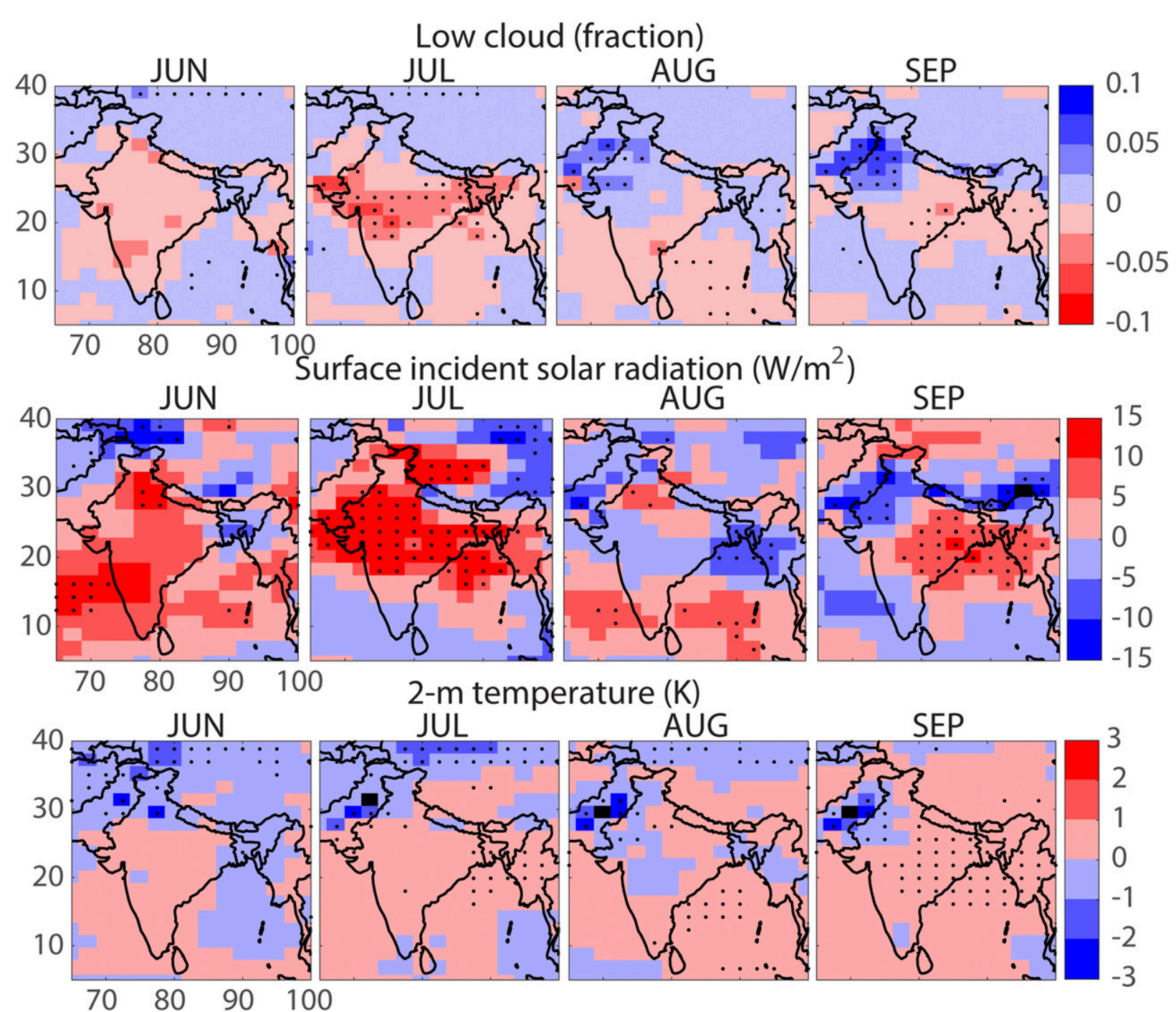

FIG. 4. The 50-yr-average changes in (top) the low cloud fraction, (middle) the surface incident solar radiation, and (bottom) 2-m air temperature from June to September (IRR minus CTRL; black dots mark grid cells with $p<0.05$ ).

is not comparable with the hypothetical ISMR difference because the actual difference is a result of combined factors influencing ISMR; however, we compare the two differences to examine their regional variabilities and the interactions (positive or negative) between the irrigation and the other combined factors.

The paired plots in Fig. 5, as mentioned in the section "Model and data," show the "projected" variability, which was projected using the "observed" IITM observation, and the comparison of difference of ISMR between "IRR - CTRL" and "Observed - Projected" over all-India and five subregions (see Fig. S2 for the map). Since India started the irrigation development from the 1950s with a rapid growth in the 1970s, the impact of irrigation on ISMR is assumed to be negligible during 1881-1971 [denoted by the training period (TP) hereafter]. The baseline time series in 1972-2003 [denoted by the projected period (PP) hereafter], which had been noted in Naidu et al. (2015), was projected as the sum of a linear trend $L$ and a cyclic function $S$ fitted to the time series of rainfall in $\mathrm{TP}$ :

$$
\begin{aligned}
& S=a_{0}+a_{1} \sin (\omega t)+a_{2} \cos (\omega t) \text { and } \\
& L=b_{0}+b_{1} t,
\end{aligned}
$$

where $a_{0}, a_{1}$, and $a_{2}$ are constants for the cyclic function, $\omega$ is angular frequency ( $\omega=2 \pi /$ period), $t$ is time (years), period is the duration for an entire cycle (65 years is assumed), and $b_{0}$ and $b_{1}$ are constants for the linear trend $L$. 

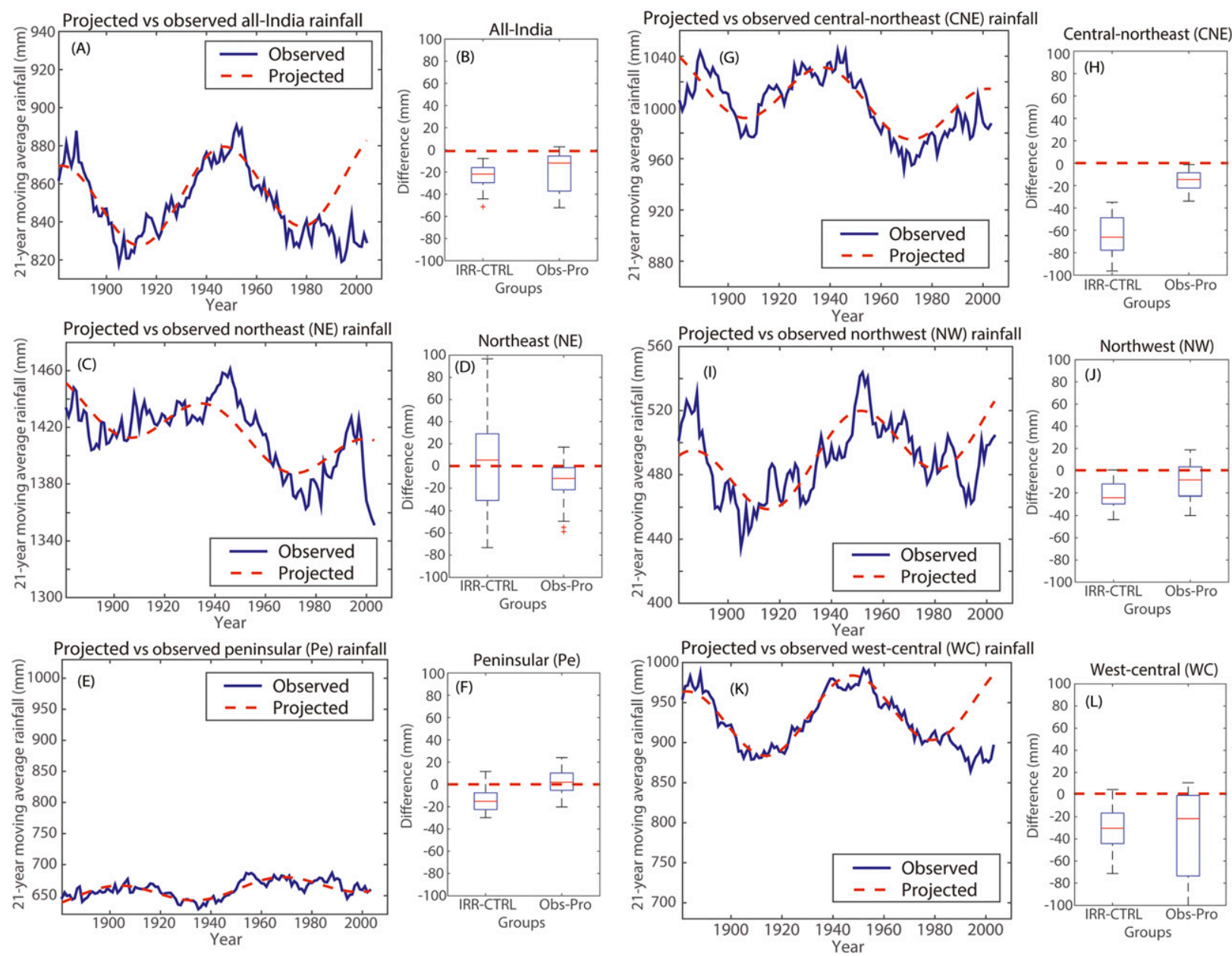

FIG. 5. (left),(right center) Comparison of 21-yr-moving-average JJAS rainfall time series between the observed and the projected and (left center),(right) the comparison of the regional variability of JJAS rainfall between the simulated (IRR - CTRL) and the projected (Obs - Pro) differences over (a),(b) all-India and the (c),(d) northeast, (e),(f) peninsular, (g),(h) central-northeast, (i),(j) northwest, and (k),(l) west-central regions.

The red dotted line in Figs. 5a, 5c, 5e, 5g, 5i, and 5k, projected from the moving-averaged ISMR in TP, represents a hypothetical June-September (JJAS) precipitation pattern without irrigation and other influencing factors on the precipitation from 1972. This projected difference in $\mathrm{PP}$, therefore, was compared to the difference of ISMR between CTRL and IRR simulations. In other words, the boxplots in Figs. 5b, 5d, 5f, $5 \mathrm{~h}, 5 \mathrm{j}$, and $5 \mathrm{l}$ compare the hypothetical change from projected to observed in PP and the simulated change from CTRL to IRR. When the majority of the blue box (data between the 25th and 75th percentiles) is below zero (red dashed line), either IRR - CTRL or Observed - Projected (Obs - Pro) is stated as "negative" as shown in Table 1. Summary results from Fig. 5 marked with $p$ values from the Student's $t$ test are presented in Table 1.
It is important to mention the weaknesses and limitations of this analysis. The "projection" by a simple statistical model is not based on the causality governed by fundamental climate physics. However, it is commonly used to quantify anomalous deviation of the process from the expected trend and cyclicity in numerous climate research (DelSole and Shukla 2002; Rajeevan et al. 2007; Sahai et al. 2003) and often provides important insights into hypothetical processes intertwined in the complex processes. To avoid spurious trends and periodicity in the projection stemming from overparameterization and to make the model robust, the choice of the model complexity was made carefully by checking the Akaike information criteria (AIC) and the Bayesian information criteria (BIC). Moreover, the statistical significance of the results was quantified using the Student's $t$ test to ensure that there was no further 
TABLE 1. Comparison between the changes of the simulated and observed ISMR. Asterisks specify $p$ values: $*$ indicates $p<0.05$;

** indicates $p<0.01$.

\begin{tabular}{lccccc}
\hline \hline \multicolumn{1}{c}{ Residuals } & All-India, west-central & Central-northeast & Northwest & Peninsular & Northeast \\
\hline Observed - Projected & Negative** & Negative* & Negative & Insignificant & Negative \\
IRR - CTRL & & Negative** & & Negative & Insignificant \\
\hline
\end{tabular}

increase of the model complexity with reduced robustness of the model. Finally, the smoothing (e.g., the aforementioned 21-yr-moving-average time series) was applied to emphasize the trend and cyclic features of ISMR that are masked by ISMR's high interannual variability on the basis of the proposal by Naidu et al. (2015). One value of this analysis is that the comparison between IRR - CTRL and Obs - Pro shown in Fig. 5 can indicate the sign of potential effect (i.e., to enhance or to weaken) on the ISMR from other factors (excluding the influence of irrigation development). Figure 5 also compares the simulated irrigation-induced effect and the projected combined influence on the ISMR at the regional level for the first time. The results demonstrate the regionwise hypothetical differences in the response of the ISMR to the irrigation alone and the combined factors.

As shown in Table 1 and Fig. 5, the decreases in rainfall are comparable between IRR - CTRL and Observed - Projected over the all-India, west-central, central-northeast, and northwest regions, although the difference of the northwest region is insignificant for Observed - Projected. The simulated reduction (IRR CTRL) in the peninsular region is, however, not found in Observed - Projected. Next, a hypothetical decrease in ISMR over the northeast is found in Observed Projected but not in the simulation. Decreases in the observed ISMR against the hypothetical baseline time series over these regions in 1972-2003 are consistent with the results of current and other studies (Lee et al. 2009; Singh et al. 2014). When comparing the anomalous variation between the IRR - CTRL and Obs - Pro, taking Fig. $5 b$ as an example, the difference indicates that the influence of other factors (excluding the influence of irrigation development) could possibly result in less reduction (a higher position of the middle value) of the ISMR but with a higher variability (a wider range between the 25th and 75th percentiles). Thus, it is likely that the effect of irrigation is opposite to the effect of other factors for all of India, although this speculation needs more evidence to be confirmed. Additionally, the results demonstrate the regionwise hypothetical differences in the response of the ISMR to the irrigation alone or the combined factors. For instance, the less reduction, to different extents, of JJAS rainfall in Obs - Pro when compared with IRR - CTRL was found over the central-northeast (CNE), the northwest $(\mathrm{NW})$, and the peninsular $(\mathrm{Pe})$ regions, along with all of India. In contrast, the combined effect in the NE likely reduces the JJAS rainfall while irrigation slightly increases it with a large variability.

\section{c. Potential mechanisms of rainfall changes}

\section{1) Changes IN LAND SURFACE STATES AND ENERGY FLUXES}

Figure S3 describes the interannual variation of monthly soil moisture (SM) averaged over the top $10 \mathrm{~cm}$ of soil column in the entirety of India. The lowest SM of $21-24 \mathrm{~kg} \mathrm{~m}^{-2}$ is observed in March, while SM reaches the highest level $\left(35 \mathrm{~kg} \mathrm{~m}^{-2}\right)$ in August and September. There are relatively larger differences of SM between the CTRL and IRR cases in the drier season from October to March because irrigation presumably plays an important role in wetting the drier soil due to low rainfall. The significant increases in SM in the IRR case, except in June and July, reveal that irrigation leads to the increased SM throughout the year, especially during the dry season. It would, in turn, modulate the regional SM-driven boundary layer processes such as the increase in ET, which is confirmed by the modeled results and the satellite-derived product (Wey et al. 2015).

As in SM, ET (see Fig. S4) exhibits a strong seasonal variation with the lowest level of $1-1.5 \mathrm{~mm} \mathrm{day}^{-1}$ in January and the highest level of approximately $3 \mathrm{~mm} \mathrm{day}^{-1}$ in July and August. The increased ET in the IRR case is the most noticeable during the dry cropping season from October to April. In addition, the increases remain statistically significant throughout the year except for June. In fact, the insignificant increase in ET in June, the onset of summer monsoon, is associated with the spatial (see the difference of June between Figs. 7a and 7b) and temporal (interannual; see the scatterplot in Fig. S4) variability.

The reference height $(2 \mathrm{~m})$ temperature with a strong seasonality reaches the highest level in May (see Fig. S5). The reduction of 2-m temperature in the IRR case is statistically significant throughout the year except for the period of ISMR (see Fig. S5) when averaged over the entirety of India. It is worth noting here that the statistically significant increases in ET in the IRR case did not lead to the corresponding decreases in 2-m temperature. 


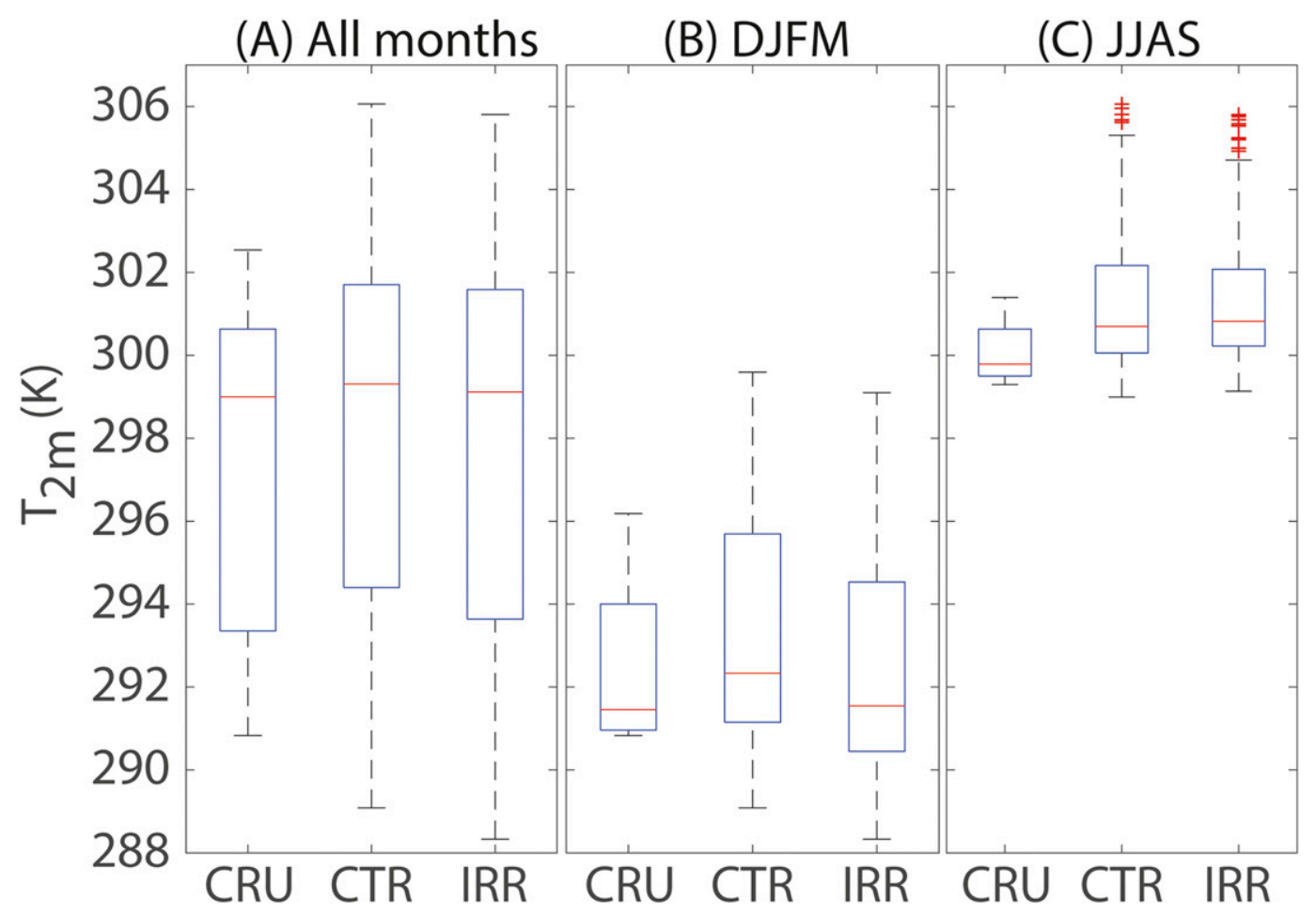

FIG. 6. Comparison of the seasonal 2-m air temperature averaged over the entire country during (a) all months, (b) DJFM, and (c) JJAS between the observed (CRU TS 3.2 in 2000) and the simulated (the results of the second 50 years in CTRL and IRR) cases.

When compared with the CRU observations of year 2000 for all months in Fig. 6a, the model tended to overestimate the 2-m air temperature when averaged over the entirety of India. However, there was a noticeable reduction/improvement during wintertime [December-March (DJFM)] from the CTRL to IRR product, while both cases varied in a similar range during summertime (JJAS). With the irrigation-induced increases in SM and ET, the insignificant decreases in 2-m temperature during summertime urge the investigation into the relationship between changes in $2-\mathrm{m}$ temperature and irrigation (SM anomaly) via analyzing the changes in low cloud cover and energy balance components.

Figure 4 illustrates the effects of irrigation (IRR CTRL) on the low cloud cover, surface incoming shortwave radiation, and 2-m temperature, respectively, from June to September. The increases in surface incoming shortwave radiation are found over western Uttar Pradesh and the Arabian Sea (see the middle row of Fig. 4) in June. The reduction of the 2-m temperature in June is limited only in the northern irrigation area. In July, the decrease in low cloud cover along with the reduced rainfall (Fig. 3) allow more incoming shortwave radiation to reach the northwest and north-central regions of the Indian subcontinent, as shown in Fig. 4. However, there are significant decreases in 2-m temperature only in the northwest Indian subcontinent with heavy irrigation. Since the evaporative cooling along with the change of incoming solar radiation simultaneously affect 2-m temperature, the change of ET induced by irrigation was examined over the region of interest. There are significant increases in July ET over the entirety of India, especially in the northwest region (see in Fig. 7a), that can partially explain the offset of the potential increase in 2-m temperature caused by enhanced surface incoming shortwave radiation. The causal relationship between irrigation and higher ET is also reported in previous studies (de Rosnay et al. 2003; Douglas et al. 2009, 2006; Saeed et al. 2009; Teluguntla et al. 2013).

In August and September with heavy irrigation, low cloud cover increased over the northwest Indian subcontinent (see top row of Fig. 4). Next, the changes in incident solar radiation (see middle row of Fig. 4) look consistent with the net effect on rainfall. For example, reduced rain with less surface incoming shortwave radiation is located in Punjab and Haryana, while increases in rain and more surface incoming shortwave radiation are found in the northern Bay of Bengal in 
(A) Punjab and Rajasthan

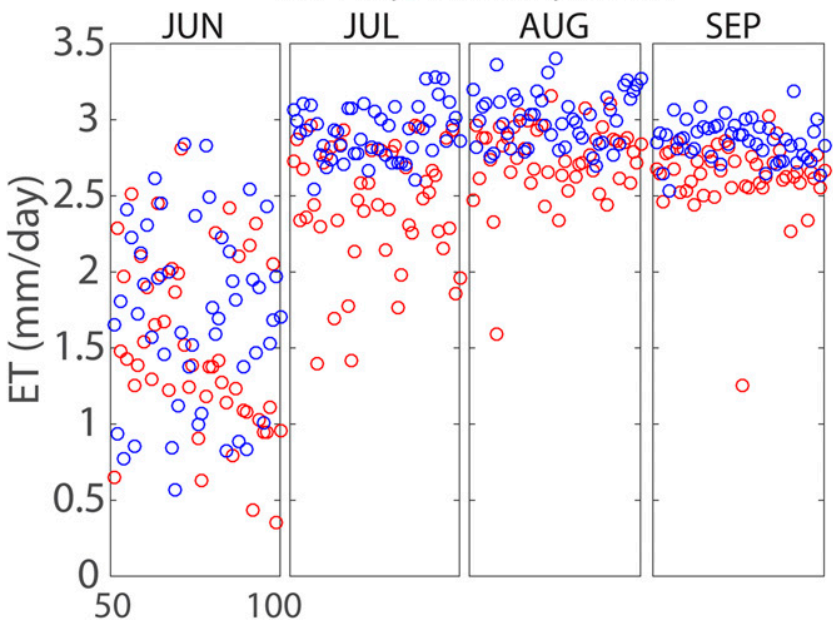

(B) The entire India

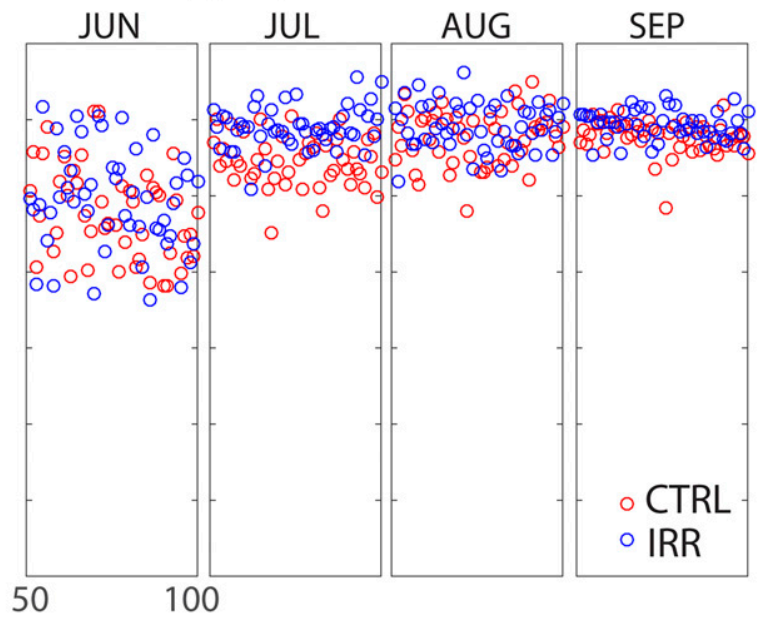

FIG. 7. Variability of monthly evapotranspiration in the second 50 years over (a) Punjab and Rajasthan and (b) the entirety of India for the CTRL and IRR cases from June to September.

August. The patched increases and decreases in incoming shortwave radiation due to stronger irrigation and reduced rainfall over northwest India are matched with changes in 2-m temperature in August. In September, the reduction of incoming shortwave radiation due to the irrigation-induced increase in low cloud cover leads to the decreased 2-m air temperature over northwest India. In contrast, the increased incoming shortwave radiation caused by the reduction of low cloud cover relating to the decreased rainfall caused the increase in 2-m air temperature over northeast India. The vertically integrated atmospheric moisture components during summertime are further examined (not shown here). The reduced convergence on the east and the increased ET on the west can partially explain the spatial variability of low cloud cover in September. The convergence dominates the change of rainfall during summertime with the high influence from irrigationinduced ET over some heavily irrigated areas.

The above findings can be partially supported by the changes in the energy balance components shown in Fig. 8. Changes in sensible heat flux (SHF), latent heat flux (LHF), and the incoming shortwave radiation due to the varying low cloud cover simultaneously modulate 2-m air temperature during summertime. In Fig. 8, the increases in incoming shortwave radiation spread over wider north India excluding the northwest region due to the irrigation-induced increased low cloud cover. The

\section{JJAS energy balance components (IRR minus CTRL)}
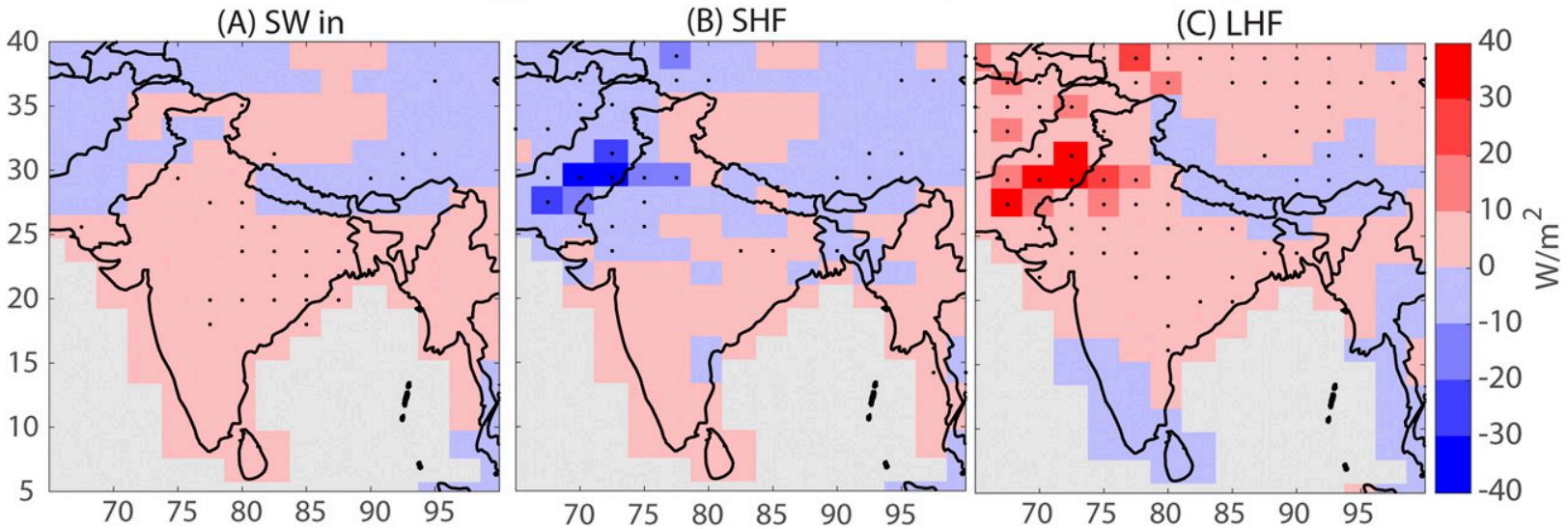

FIG. 8. The 50-yr-average changes in JJAS energy balance components including (a) the incoming shortwave radiation flux, (b) sensible heat flux, and (c) latent heat flux (IRR minus CTRL; black dots mark grid cells with $p<0.05$ ). 
reduced SHF is mostly located over northwest India while the major increases in LHF also dominate over the entire northern part of India.

In Fig. 8, the expected cooling due to the reduced SHF over northwest India is possibly compensated by the wider increases in incoming shortwave radiation along with decreased low cloud cover due to less rainfall in July and August. Therefore, the changes in 2-m air temperature are significant only over the heavily irrigated regions. As expected, there is a strong cooling over the heavily irrigated Indus basin. Figure 9 and Fig. 4 delineate the large spatial heterogeneity of changes in 2- $\mathrm{m}$ air temperature in India during summertime. According to Fig. 10, the spatial distribution of the simulated 2-m air temperature is comparable to the CRU observation although the majority of the region appears to be overestimated. The overestimation is largely due to use of the year-2000 forcing (all major anthropogenic factors) because there was an accelerated warming across the globe after 1980 .

\section{2) LARGE-SCALE ATMOSPHERIC CIRCULATION}

The Indian summer monsoon (ISM) is primarily induced by a large-scale thermal contrast between the Indian Ocean and the Indian subcontinent while the

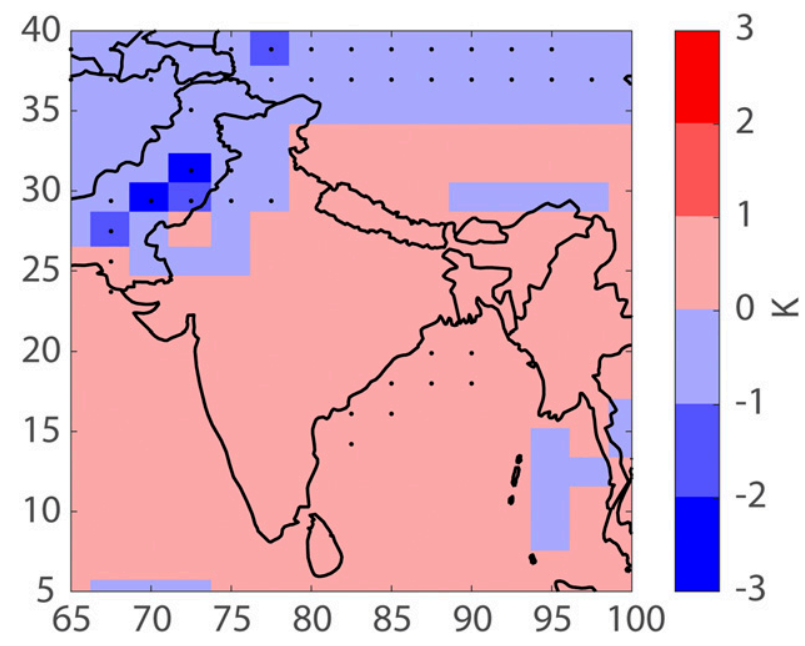

FIG. 9. The 50-yr-average JJAS 2-m air temperature changes (IRR minus CTRL; black dots mark grid cells with $p<0.05$ ).

fraction of precipitation locally recycled by convective storms is relatively low, especially over western and northern India (0.01\% in Punjab and Haryana; $0.07 \%$ in Rajasthan and northern Gujarat) (Pathak et al. 2014). This confirms the importance of the large-scale atmospheric circulation for ISMR. This section aims to
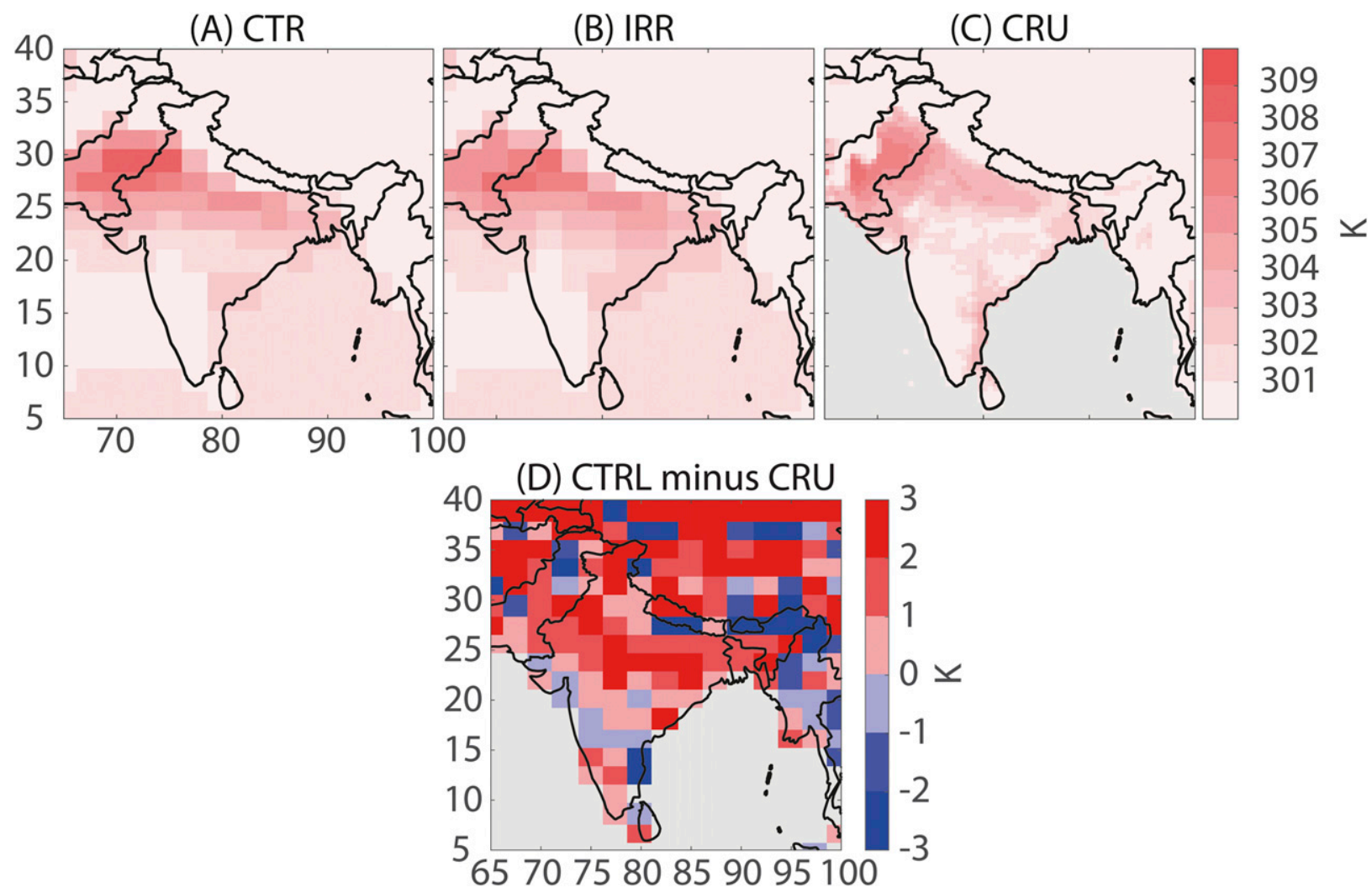

FIG. 10. The 50-yr-average JJAS 2-m air temperature for (a) CTRL, (b) IRR, (c) CRU, and (d) CTRL minus CRU. 


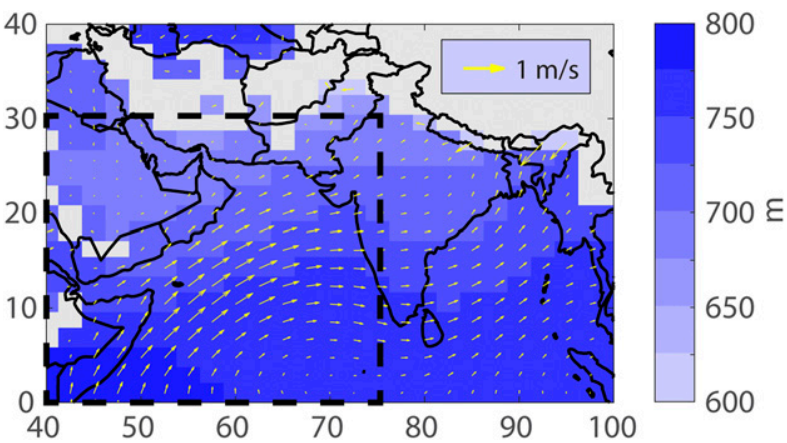

FIG. 11. The 50-yr IRR average low-level wind (arrows) and geopotential height (shading) maps (there is no $925-\mathrm{hPa}$ level in gray area).

describe the irrigation-induced changes in wind fields along with geopotential heights at different atmospheric levels during the period of ISMR.

The low-level $(925 \mathrm{hPa})$ wind in the IRR case is predominantly southwesterly from the western Indian Ocean, which progresses through the Indian subcontinent as shown in Fig. 11. However, the IRR CTRL result at the same level (see Fig. 13) shows a northeasterly wind principally flowing from northwest India toward the northern Indian Ocean. This indicates that the strength of prevailing winds bringing moist air to the Indian subcontinent during summertime reduced significantly in the IRR case. The irrigation-induced low-level winds may weaken the prevailing summer monsoon wind, although the geopotential height residuals range from 2 to $5 \mathrm{~m}$, which are relatively small.

To evaluate the comprehensive atmospheric circulation induced by irrigation, Fig. 12 shows the vertical velocity profile averaged over the $40^{\circ}-75^{\circ} \mathrm{E}$ region, in which the aforementioned $925-\mathrm{hPa}$ wind anomaly caused by irrigation is included (see the dashed box in Fig. 11) from June to September. There are two significant downward velocity fields over $30^{\circ} \mathrm{N}$ at the $925-\mathrm{hPa}$ level and $15^{\circ}-20^{\circ} \mathrm{N}$ at the $700-\mathrm{hPa}$ level, and an insignificant upward velocity field near the equator [significant in July-September (JAS); not shown here]. Therefore, the irrigation-induced southwestward wind at low-level atmosphere from the heavily irrigated region over $30^{\circ} \mathrm{N}$ can be linked with the downward velocity at $30^{\circ} \mathrm{N}$ and the upward velocity near the equator.

In the high-level atmosphere shown in Fig. 13 (see 400-, 500-, and 600-hPa levels), there are southwesterly wind anomalies over $10^{\circ}-15^{\circ} \mathrm{N}$ latitude $(p<0.05)$, which could be related to the upward wind velocity near the equator (significant in JAS) observed in Fig. 12 and the irrigation-induced northeasterly wind anomalies from the land shown in the low-level atmosphere in

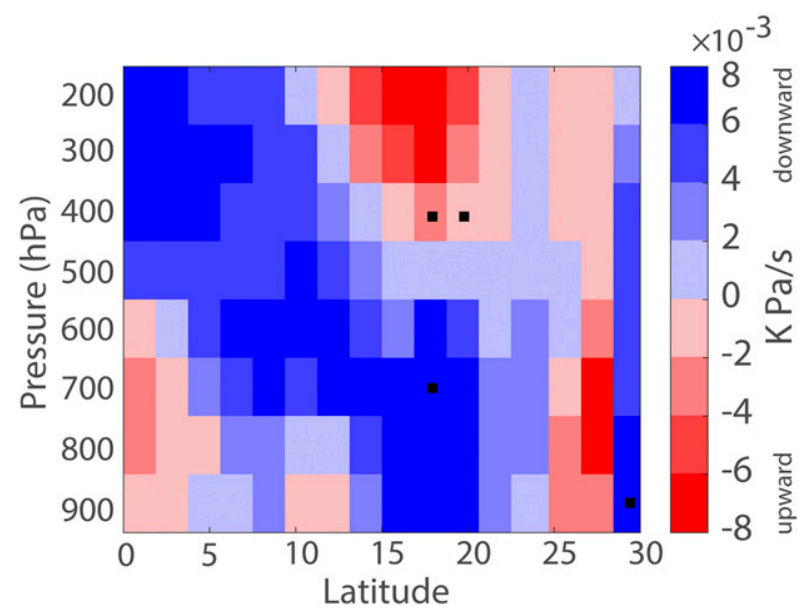

FIG. 12 . The 50 -yr-average vertical velocity profile averaged over $40^{\circ}-75^{\circ} \mathrm{N}$

Fig. 12. The irrigation-induced vertical depth of circulation in summertime can reach up to the $300-\mathrm{hPa}$ level, which is shallower compared with the result in Wey et al. (2015), and the southwesterly wind at the high level appears to join the southwestward wind near ground level around $10^{\circ}-15^{\circ} \mathrm{N}$. The possible reason for the shallower vertical circulation could be that the wind field anomaly induced by irrigation weakens the prevailing monsoon instead of enhancing the monsoon during wintertime. Also, a weaker Hadley circulation exists during summertime, which could affect the wind field anomaly as well.

The irrigation-induced changes in vertically integrated total precipitable water differences shown in Fig. 14 could hint at the potential decreases in the ISMR. There are significant reductions of the total precipitable water over north India during summertime. This reduction possibly results from the aforementioned weakened moist ISM winds because irrigation appears not to increase the precipitable water even over the heavily irrigated regions.

To examine the hypothesis that the weakened landsea thermal contrast leads to reduced ISM wind, we computed the thermal contrast induced by irrigation (IRR - CTRL) between the land and sea shown in the inner plot in Fig. S15. A reduction of this value corresponds to a decreased land-sea temperature gradient. Overall, there are more negative bars, which signifies the SSTs are frequently higher than the land surface temperatures over northwest India. This evidence supports our hypothesis that irrigation modulates the largescale atmospheric circulation, which can be associated with weakened land-sea thermal contrasts in the IRR case. Similarly, the intensified wintertime monsoonal circulation is attributed to irrigation-induced stronger land-sea temperature contrast (Wey et al. 2015). 


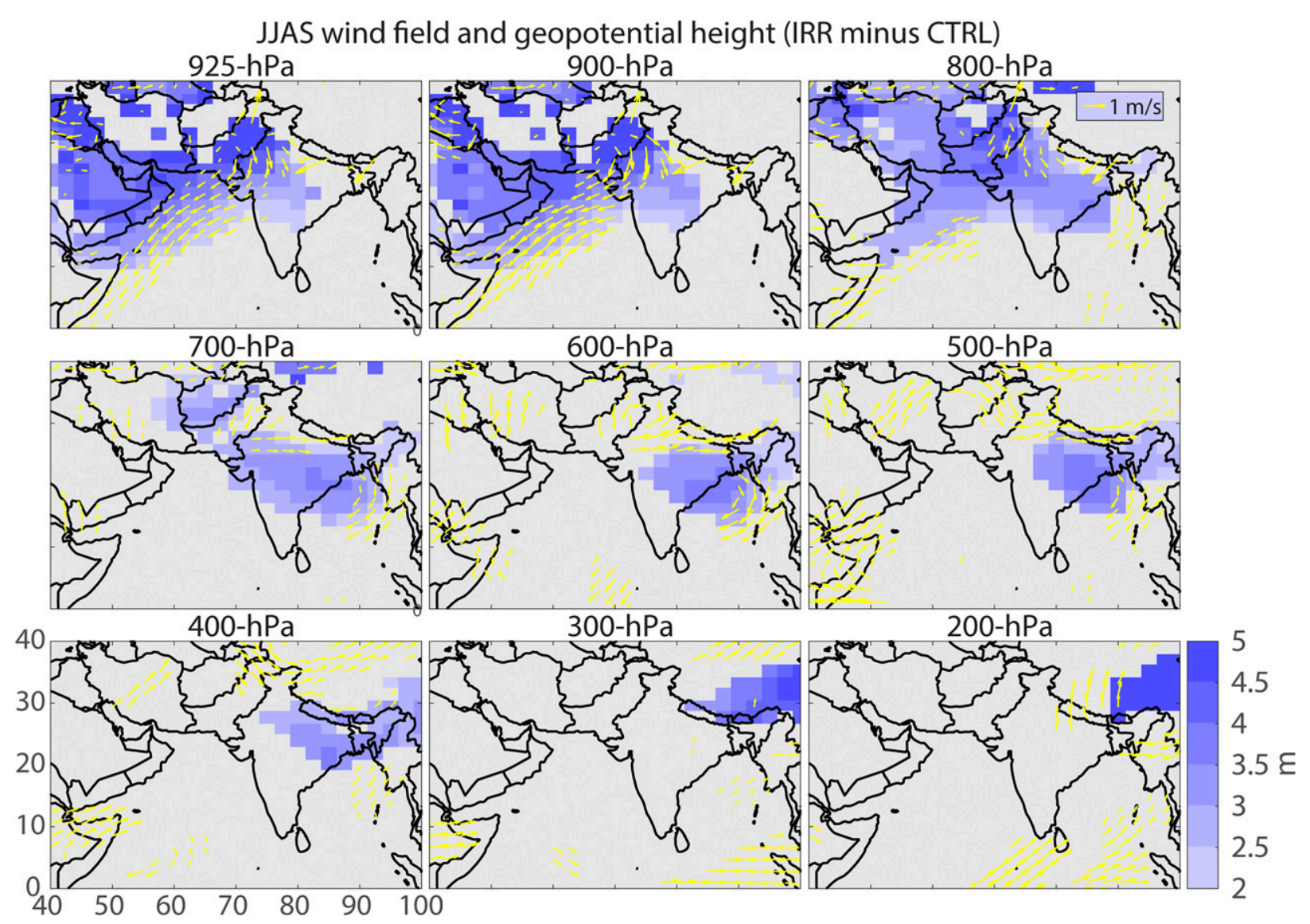

FIG. 13. Wind fields (arrows) and geopotential height residuals (shading) from 925- to 200-hPa level (only results with $p<0.05$ are shown).

\section{Conclusions}

This study showed the effect of irrigation on land surface variables, rainfall, and large-scale atmospheric circulation by analyzing fully coupled simulations, and these results were compared to the observational records. Although the fully coupled model simulations were conducted based on a set of simplified atmospheric and irrigation scenarios, the sensitivity test of this work is intended to demonstrate the evolution of spatial pattern and competition between the positive and negative feedback at the different stages of summer monsoon months.

The observed ISMR, presented as the time series of 21-yr moving average in 1972-2003, showed a statistically significant reduction when compared with the projected levels derived from a cyclic model in 18711971. The reductions over all of India, and the northwest, west-central, and central-northeast regions are comparable to the modeled changes from the CTRL to IRR cases for a 50-yr average. This comparison not only supports the modeled ISMR changes induced by irrigation, but also the hypothesis that irrigation that commenced in the 1950s caused a reduction of the long-term
ISMR, although the accurate irrigation water quantities are time-varying. The variability of land surface state and the large-scale atmospheric circulation exhibits the following characteristics:

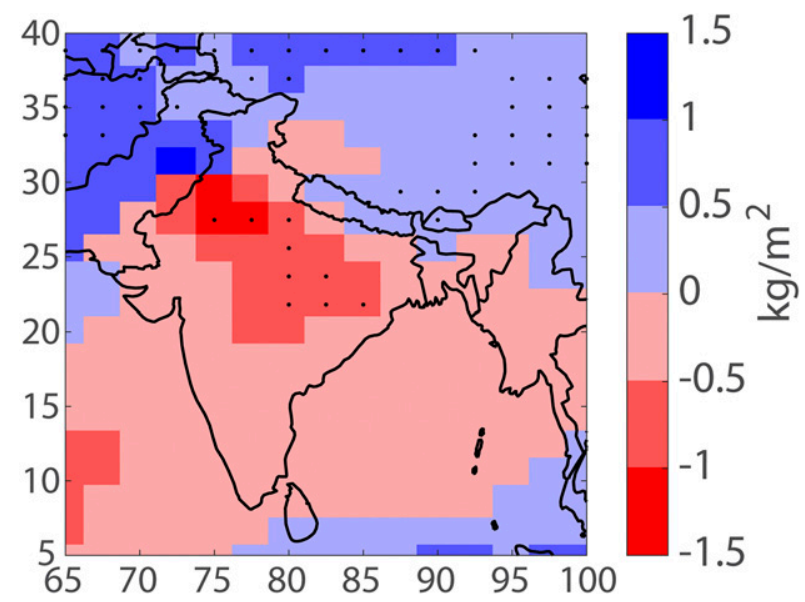

FIG. 14. The 50-yr-average changes in total vertically integrated precipitable water (IRR minus CTRL; black dots mark grid cells with $p<0.05)$. 
- SM and ET show the statistically significant increases in most months $(p<0.01)$ in the IRR case.

- The 2-m air temperature decreases over heavily irrigated northwest India during summertime, especially in August and September, despite the fact that the reduction is insignificant in the ISM period when averaged over the entire country.

- Over the northwest and north-central regions of India in July, the decrease in low cloud cover allows more incoming shortwave radiation, which in turn cancels off the irrigation-induced evaporative cooling effect, which is supported by increased ET. Next, in September, heavy irrigation simultaneously causes a decrease (increase) in incoming shortwave radiation due to an increase (a decrease) in low cloud cover over northwest (northeast) India. The variability in $2-\mathrm{m}$ air temperature, therefore, depends on the irrigation pattern and the local land-atmosphere coupling because of their influence on energy balance components via the variability of SM-associated water vapor.

- The simulated weakened July rainfall is linked to the irrigation-induced decrease in low-level wind that brings moist air from the ocean. This is supported by the irrigation-induced opposite-to-prevailing ISM winds in lower levels of the atmosphere, and the connecting vertical velocity, which demonstrates the weakened large-scale atmospheric circulation initiating the summer monsoon. The above findings show, not being fully investigated in previous works (Cook et al. 2015), that the negative feedback mechanism behind the irrigation-induced reduced July rain is explained by changes in wind fields and vertical velocities at different atmospheric levels during summertime and is shown in a fully coupled simulation considering other anthropogenic forcings (GHGs and anthropogenic aerosols, etc.). The smaller temperature gradient between northwest India and the north Indian Ocean in the IRR case reconfirms the above argument.

- Rainfall over some parts of the moderately to heavily irrigated regions increases in August and September as a net result of competing influence between positive and negative feedback between the irrigation-induced SM anomaly and rainfall. This has very important implications that simultaneous occurrence of the positive and the negative land-atmosphere feedback can have a net effect of either increasing or decreasing monsoon rainfall. The combined effect of these two feedback mechanisms was reported in the previous literature-for example, Seneviratne et al. (2010) - but this work shows that the competing feedback might reduce the net impact of the negative feedback.
Demonstrating the series of changes caused by the large-scale irrigation and potentially the positive and negative land-atmosphere feedback between the soil moisture anomaly and ISMR associated with the largescale atmospheric circulation at the different stages of the summer monsoon months makes the current study unique compared to previous studies (Guimberteau et al. 2012; Shukla et al. 2014). Guimberteau et al. (2012) found irrigation-induced decreases in rainfall, especially in June, over the west coast of India along with a reduction of oceanic wind in May and June. This is an earlier reduction of monsoon activity compared to the current study that a significant reduced July rainfall was found over northern India that is comparable to the observational analysis by Lee et al. (2009). In terms of the relationship between atmospheric temperature and irrigation intensity, Shukla et al. (2014) argued that irrigation rate is highly correlated with the land-sea temperature differences. In the current study, the relationship between irrigation and land surface temperature varies by region, and irrigation can contribute to both increasing and decreasing the surface temperature via multiple feedback mechanisms. Wey et al. (2015) have reported that an increased land-sea thermal contrast caused by the land surface cooling amplifies the Indian monsoon winds during wintertime. However, in summer, the irrigation-induced weaker land-sea thermal contrast hampers the prevailing ISM winds, which in turn reduce precipitation over India. The reduction induced by the negative feedback became weaker when irrigation increased to a certain level, such as in the northwest region in September; this evolution of spatial variability during summertime has not yet been demonstrated before. Our hypothesized land-atmosphere interaction, simulated in fully coupled simulations, explains these contrasting effects of irrigation on the Indian summer and winter monsoon systems. Using the 1991-2000 climatology data with heavy irrigation in the simulation might have resulted in the overestimated impact of irrigation, but this sensitivity test tends to reveal the evolution of spatial variability of competition between the positive and negative feedback mechanisms. In the future, simulations simultaneously considering other factors such as SST changes and LULCC, along with a more realistic irrigation water quantity, would improve the realism of simulating the relative contribution of irrigation, among other factors.

Acknowledgments. The authors thank the Climate and Global Dynamics Laboratory (CGD) at the National Center for Atmospheric Research (NCAR) for maintaining the CESM. We also thank the Indian Institute of Tropical Meteorology (IITM) for making 
rainfall observation records available and the Indian Meteorological Department (IMD) for producing and providing the gauged-based rainfall data (https://www. tropmet.res.in/). We thank the editor and anonymous reviewers for their valuable comments that helped us to improve the manuscript. The simulation results analyzed in this work are available upon request (chihchungc@student. unimelb.edu.au). This study was supported by the Melbourne International Research Scholarship (MIRS) and the Ministry of Science and Technology, Taiwan, Grant MOST 106-2111-M-002-010-MY4.

\section{REFERENCES}

Agnihotri, R., K. Dutta, R. Bhushan, and B. Somayajulu, 2002: Evidence for solar forcing on the Indian monsoon during the last millennium. Earth Planet. Sci. Lett., 198, 521-527, https:// doi.org/10.1016/S0012-821X(02)00530-7.

Berkelhammer, M., A. Sinha, M. Mudelsee, H. Cheng, R. L. Edwards, and K. Cannariato, 2010: Persistent multidecadal power of the Indian summer monsoon. Earth Planet. Sci. Lett., 290, 166-172, https://doi.org/10.1016/j.epsl.2009.12.017.

Bollasina, M. A., Y. Ming, and V. Ramaswamy, 2011: Anthropogenic aerosols and the weakening of the South Asian summer monsoon. Science, 334, 502-505, https://doi.org/10.1126/ science.1204994.

,,,--- M. D. Schwarzkopf, and V. Naik, 2014: Contribution of local and remote anthropogenic aerosols to the twentieth century weakening of the South Asian monsoon. Geophys. Res. Lett., 41, 680-687, https://doi.org/10.1002/ 2013GL058183.

Boucher, O., G. Myhre, and A. Myhre, 2004: Direct human influence of irrigation on atmospheric water vapour and climate. Climate Dyn., 22, 597-603, https://doi.org/10.1007/ s00382-004-0402-4.

Chase, T., J. Knaff, R. Pielke Sr., and E. Kalnay, 2003: Changes in global monsoon circulations since 1950. Nat. Hazards, 29, 229254, https://doi.org/10.1023/A:1023638030885.

Cook, B. I., S. P. Shukla, M. J. Puma, and L. S. Nazarenko, 2015: Irrigation as an historical climate forcing. Climate Dyn., 44, 1715-1730, https://doi.org/10.1007/s00382-014-2204-7.

DelSole, T., and J. Shukla, 2002: Linear prediction of Indian monsoon rainfall. J. Climate, 15, 3645-3658, https://doi.org/ 10.1175/1520-0442(2002)015<3645:LPOIMR > 2.0.CO;2.

de Rosnay, P., J. Polcher, K. Laval, and M. Sabre, 2003: Integrated parameterization of irrigation in the land surface model ORCHIDEE. Validation over Indian Peninsula. Geophys. Res. Lett., 30, 1986, https://doi.org/10.1029/2003GL018024.

Döll, P., and S. Siebert, 2002: Global modeling of irrigation water requirements. Water Resour. Res., 38, 1037, https://doi.org/ 10.1029/2001WR000355.

Douglas, E. M., D. Niyogi, S. Frolking, J. B. Yeluripati, R. A. Pielke, N. Niyogi, C. J. Vörösmarty, and U. C. Mohanty, 2006: Changes in moisture and energy fluxes due to agricultural land use and irrigation in the Indian monsoon belt. Geophys. Res. Lett., 33, L14403, https://doi.org/10.1029/2006GL026550.

, A. Beltrán-Przekurat, D. Niyogi, R. A. Pielke, and C. J. Vörösmarty, 2009: The impact of agricultural intensification and irrigation on land-atmosphere interactions and Indian monsoon precipitation-A mesoscale modeling perspective.
Global Planet. Change, 67, 117-128, https://doi.org/10.1016/ j.gloplacha.2008.12.007.

Dwivedi, S., B. Goswami, and F. Kucharski, 2015: Unraveling the missing link of ENSO control over the Indian monsoon rainfall. Geophys. Res. Lett., 42, 8201-8207, https://doi.org/ 10.1002/2015GL065909.

Goswami, B. N., M. S. Madhusoodanan, C. P. Neema, and D. Sengupta, 2006: A physical mechanism for North Atlantic SST influence on the Indian summer monsoon. Geophys. Res. Lett., 33, L02706, https://doi.org/10.1029/2005GL024803.

Guimberteau, M., K. Laval, A. Perrier, and J. Polcher, 2012: Global effect of irrigation and its impact on the onset of the Indian summer monsoon. Climate Dyn., 39, 1329-1348, https:// doi.org/10.1007/s00382-011-1252-5.

Halder, S., S. K. Saha, P. A. Dirmeyer, T. N. Chase, and B. N. Goswami, 2016: Investigating the impact of land-use landcover change on Indian summer monsoon daily rainfall and temperature during 1951-2005 using a regional climate model. Hydrol. Earth Syst. Sci., 20, 1765-1784, https://doi.org/10.5194/ hess-20-1765-2016.

Harris, I., P. Jones, T. Osborn, and D. Lister, 2014: Updated highresolution grids of monthly climatic observations-The CRU TS3.10 dataset. Int. J. Climatol., 34, 623-642, https://doi.org/ 10.1002/joc.3711.

Hurrell, J. W., and Coauthors, 2013: The Community Earth System Model: A framework for collaborative research. Bull. Amer. Meteor. Soc., 94, 1339-1360, https://doi.org/10.1175/ BAMS-D-12-00121.1.

Koster, R. D., and Coauthors, 2004: Regions of strong coupling between soil moisture and precipitation. Science, 305, 11381140, https://doi.org/10.1126/science.1100217.

Kueppers, L. M., M. A. Snyder, and L. C. Sloan, 2007: Irrigation cooling effect: Regional climate forcing by land-use change. Geophys. Res. Lett., 34, L03703, https://doi.org/10.1029/ 2006 GL028679.

Kumar, K. K., B. Rajagopalan, and M. A. Cane, 1999: On the weakening relationship between the Indian monsoon and ENSO. Science, 284, 2156-2159, https://doi.org/10.1126/ science.284.5423.2156.

Lee, E., T. N. Chase, B. Rajagopalan, R. G. Barry, T. W. Biggs, and P. J. Lawrence, 2009: Effects of irrigation and vegetation activity on early Indian summer monsoon variability. Int. J. Climatol., 29, 573-581, https://doi.org/10.1002/joc.1721.

Lo, M. H., and J. S. Famiglietti, 2013: Irrigation in California's Central Valley strengthens the southwestern US water cycle. Geophys. Res. Lett., 40, 301-306, https://doi.org/10.1002/ grl.50108.

Lobell, D., G. Bala, A. Mirin, T. Phillips, R. Maxwell, and D. Rotman, 2009: Regional differences in the influence of irrigation on climate. J. Climate, 22, 2248-2255, https://doi.org/ 10.1175/2008JCLI2703.1.

Naidu, C., A. D. Raju, G. C. Satyanarayana, P. V. Kumar, G. Chiranjeevi, and P. Suchitra, 2015: An observational evidence of decrease in Indian summer monsoon rainfall in the recent three decades of global warming era. Global Planet. Change, 127, 91-102, https://doi.org/10.1016/j.gloplacha.2015.01.010.

Niyogi, D., C. Kishtawal, S. Tripathi, and R. S. Govindaraju, 2010: Observational evidence that agricultural intensification and land use change may be reducing the Indian summer monsoon rainfall. Water Resour. Res., 46, W03533, https://doi.org/ 10.1029/2008WR007082.

Pathak, A., S. Ghosh, and P. Kumar, 2014: Precipitation recycling in the Indian subcontinent during summer monsoon. 
J. Hydrometeor., 15, 2050-2066, https://doi.org/10.1175/ JHM-D-13-0172.1.

Puma, M. J., and B. I. Cook, 2010: Effects of irrigation on global climate during the 20th century. J. Geophys. Res., 115, D16120, https://doi.org/10.1029/2010JD014122.

Rajeevan, M., D. Pai, R. A. Kumar, and B. Lal, 2007: New statistical models for long-range forecasting of southwest monsoon rainfall over India. Climate Dyn., 28, 813-828, https://doi.org/ 10.1007/s00382-006-0197-6.

Roxy, M. K., K. Ritika, P. Terray, R. Murtugudde, K. Ashok, and B. N. Goswami, 2015: Drying of Indian subcontinent by rapid Indian Ocean warming and a weakening land-sea thermal gradient. Nat. Commun., 6, 7423, https://doi.org/10.1038/ncomms 8423 .

Sacks, W. J., B. I. Cook, N. Buenning, S. Levis, and J. H Helkowski, 2009: Effects of global irrigation on the nearsurface climate. Climate Dyn., 33, 159-175, https://doi.org/ 10.1007/s00382-008-0445-z.

Saeed, F., S. Hagemann, and D. Jacob, 2009: Impact of irrigation on the South Asian summer monsoon. Geophys. Res. Lett., 36, L20711, https://doi.org/10.1029/2009GL040625.

,-- S. Saeed, and D. Jacob, 2013: Influence of mid-latitude circulation on upper Indus basin precipitation: The explicit role of irrigation. Climate Dyn., 40, 21-38, https://doi.org/ 10.1007/s00382-012-1480-3.

Sahai, A., A. Grimm, V. Satyan, and G. Pant, 2003: Long-lead prediction of Indian summer monsoon rainfall from global SST evolution. Climate Dyn., 20, 855-863, https://doi.org/ 10.1007/s00382-003-0306-8.

Saji, N. H., B. N. Goswami, P. N. Vinayachandran, and T. Yamagata, 1999: A dipole mode in the tropical Indian Ocean. Nature, 401, 360-363, https://doi.org/10.1038/43854.

Salzmann, M., and R. Cherian, 2015: On the enhancement of the Indian summer monsoon drying by Pacific multidecadal variability during the latter half of the twentieth century. J. Geophys. Res. Atmos., 120, 9103-9118, https://doi.org/10.1002/2015JD023313.

Schultz, N. M., X. Lee, P. J. Lawrence, D. M. Lawrence, and L. Zhao, 2016: Assessing the use of subgrid land model output to study impacts of land cover change. J. Geophys. Res. Atmos., 121, 6133-6147, https://doi.org/10.1002/2016JD025094.

Seneviratne, S. I., T. Corti, E. L. Davin, M. Hirschi, E. B. Jaeger, I. Lehner, B. Orlowsky, and A. J. Teuling, 2010: Investigating soil moisture-Climate interactions in a changing climate: A review. Earth Sci. Rev., 99, 125-161, https:// doi.org/10.1016/j.earscirev.2010.02.004.

Shukla, S. P., M. J. Puma, and B. I. Cook, 2014: The response of the South Asian summer monsoon circulation to intensified irrigation in global climate model simulations. Climate Dyn., 42, 21-36, https://doi.org/10.1007/s00382-013-1786-9.
Siebert, S., M. Kummu, M. Porkka, P. Döll, N. Ramankutty, and B. R. Scanlon, 2015: A global data set of the extent of irrigated land from 1900 to 2005. Hydrol. Earth Syst. Sci., 19,1521-1545, https://doi.org/10.5194/hess-19-1521-2015.

Singh, D., M. Tsiang, B. Rajaratnam, and N. S. Diffenbaugh, 2014: Observed changes in extreme wet and dry spells during the South Asian summer monsoon season. Nat. Climate Change, $\mathbf{4}$, 456-461, https://doi.org/10.1038/nclimate2208.

Srivastava, A., O. Srijith, S. Kshirsagar, and K. Srivastava, 2015: Has modulation of Indian summer monsoon rainfall by sea surface temperature of the equatorial Pacific Ocean, weakened in recent years? Climate Dyn., 45, 2237-2254, https:// doi.org/10.1007/s00382-015-2470-z.

Teluguntla, P., D. Ryu, B. George, and J. P. Walker, 2013: Multidecadal trend of basin-scale evapotranspiration estimated using AVHRR data in the Krishna River basin, India. Vadose Zone J., 12, https://doi.org/10.2136/vzj2012.0118.

Thiery, W., E. L. Davin, D. M. Lawrence, A. L. Hirsch, M. Hauser, and S. I. Seneviratne, 2017: Present-day irrigation mitigates heat extremes. J. Geophys. Res. Atmos., 122, 1403-1422, https:// doi.org/10.1002/2016JD025740.

Wey, H. W., M. H. Lo, S. Y. Lee, J. Y. Yu, and H. H. Hsu, 2015: Potential impacts of wintertime soil moisture anomalies from agricultural irrigation at low latitudes on regional and global climates. Geophys. Res. Lett., 42, 8605-8614, https://doi.org/ 10.1002/2015GL065883.

Wisser, D., S. Frolking, E. M. Douglas, B. M. Fekete, C. J. Vörösmarty, and A. H. Schumann, 2008: Global irrigation water demand: Variability and uncertainties arising from agricultural and climate data sets. Geophys. Res. Lett., 35, L24408, https://doi.org/10.1029/2008GL035296.

Xu, Z., R. Mahmood, Z. L. Yang, C. Fu, and H. Su, 2015: Investigating diurnal and seasonal climatic response to land use and land cover change over monsoon Asia with the Community Earth System Model. J. Geophys. Res. Atmos., 120, 1137-1152, https://doi.org/10.1002/2014JD022479.

Zeng, Y., Z. Xie, and J. Zou, 2017: Hydrologic and climatic responses to global anthropogenic groundwater extraction. J. Climate, 30, 71-90, https://doi.org/10.1175/JCLI-D-16-0209.1.

Zou, J., Z. Xie, Y. Yu, C. Zhan, and Q. Sun, 2014: Climatic responses to anthropogenic groundwater exploitation: A case study of the Haihe River basin, northern China. Climate Dyn., 42, 2125-2145, https://doi.org/10.1007/s00382-013-1995-2.

,-- C. Zhan, P. Qin, Q. Sun, B. Jia, and J. Xia, 2015: Effects of anthropogenic groundwater exploitation on land surface processes: A case study of the Haihe River basin, northern China. J. Hydrol., 524, 625-641, https://doi.org/10.1016/ j.jhydrol.2015.03.026. 